\title{
Familial benign intracranial hypertension
}

\author{
D. C. TRAVIESA ${ }^{1}$, R. J. SCHWARTZMAN ${ }^{2}$, J. S. GLASER, \\ AND PETER SAVINO \\ From the Departments of Neurology and Ophthalmology, \\ University of Miami School of Medicine, Miami, Florida, USA
}

\begin{abstract}
SYNOPSIS Three sisters with benign intracranial hypertension are reported. This is the first documentation of benign intracranial hypertension in three family members. Obesity is a striking feature in these patients as well as five of the six previously reported patients with familial benign intracranial hypertension. Pregnancy and chronic dysfunctional uterine bleeding, well known predisposing factors in this syndrome when it occurs sporadically, were present in two of the sisters. A familial metabolic defect may be responsible for the intracranial hypertension in these patients.
\end{abstract}

Pseudotumor cerebri, or benign intracranial hypertension, is a syndrome defined as increased intracranial pressure with no evidence of nervous system dysfunction other than that caused by the intracranial hypertension itself - that is, transient visual obscurations, enlarged blindspots, headache, sixth nerve palsy, papilloedema, and secondary optic atrophy (Johnston and Paterson, 1974). Some patients with benign intracranial hypertension have no clear accompanying cause but demonstrate abnormalities or alteration in endocrinological or metabolic function. These patients are, typically, young females who are obese and may be pregnant or suffering from chronic dysfunctional uterine bleeding (Greer, 1968).

The purpose of this paper is to report the occurrence of benign intracranial hypertension in three sisters who demonstrate these alterations in metabolic function.

\section{CASE REPORTS}

\section{CASE 1}

A 41 year old lady has suffered from obesity and idiopathic dysfunctional uterine bleeding for most of

\footnotetext{
1 Address for correspondence: Major D. C. Traviesa, P.O. Box 416, Letterman Army Medical Center, Presidio of San Francisco, CA 94129, USA.

2 Address for reprints: Dr R. J. Schwartzman, Department of Neurology, Woodard 4, Jackson Memorial Hospital, Miami, Florida 33136, USA.

(Accepted 25 October 1975.)
}

her adult life. She has a history of bilateral corneal dystrophy beginning in 1955 and requiring several corneal transplantations over the next few years. Her first complaint of chronic headache and transienf visual obscurations was in October 1963, at which time her vision was finger counting in the right eyee and $20 / 60$ in the left eye. Visual field examination by finger confrontation was normal. This reduction in visual acuity was thought to be consistent with the corneal dystrophy present. In April 1964, definitepapilloedema was observed in the left eye. The right fundus could not be visualized adequately. Skull radiographs were negative. The patient was lost to follow-up until July 1965 when she was hospitalized for another keratoplasty and the left fundus was reported as normal. Headaches persisted, however. In April 1966 she again complained of transient darkening of vision but also of progressive visual loss. Finally, in July 1966, papilloedema was again noted in the left eye. Visual acuity was reduced to hand movements in the right and 20/100 in the left eye, The progressive visual loss could not be explained on the basis of corneal disease. She was admitted to the neurological service at Jackson Memorial Hospital in July 1966, at which time her weight was $100 \mathrm{~kg}$ (220 pounds) and the chief complaint was transient three to four second episodes of darkening vision and chronic bifrontal headache. The patient had paleness of the left optic disc with swelling and loss of disc margins consistent with chronic papilloedema. The right disc could not be seen. Lumbar puncture revealed an opening pressure of 530 $\mathrm{mm} \mathrm{H}_{2} \mathrm{O}$ with clear, colourless fluid, containing one mononuclear cell per $\mathrm{mm}^{3}$ and total protein of $0.22 \mathrm{~g} / \mathrm{l}$. Skull radiographs revealed mild enlargement 
of the sella turcica, thinning of the dorsum sellae, and increased convolutional markings consistent with chronic intracranial hypertension. Brain scan, pneumoencephalogram, and right carotid arteriogram were normal. The patient was discharged on acetazolamide and prednisone. She received weekly lumbar punctures for two months, with the opening pressure consistently above $400 \mathrm{mmH}_{2} \mathrm{O}$. She developed worsening optic atrophy and was noted to have vision to hand movements four months after discharge. At present, the patient is blind and is otherwise well except for obesity and intermittent headache.

\section{CASE 2}

A 22 year old woman was admitted to Jackson Memorial Hospital on 14 January 1974 with a chief complaint of transient episodes of blurring and darkening of vision, headache, and horizontal diplopia upon right gaze for several weeks before admission. She was in the fourth month of pregnancy and was ingesting one tablet of multivitamins per day as prescribed by her obstetrician. She had taken birth control pills for one year but had stopped 14 months before admission. She has been obese all her life but denied menstrual disturbance or other drug ingestion. The physical examination revealed a lady weighing $88.6 \mathrm{~kg}$ (195?pounds) with a normal blood pressure and pulse rate. She was bright and alert and in no acute distress. The abnormal findings included marked papilloedema bilaterally without haemorrhages (Fig. 1). There was bilateral lateral rectus paresis, more marked on the right. Visual field examination showed enlargement of the blind spots. Visual acuity was $20 / 20$ bilaterally. Lumbar puncture revealed an opening pressure of $540 \mathrm{mmH}_{2} \mathrm{O}$ with clear colourless fluid containing no cells and a total protein of $0.14 \mathrm{~g} / \mathrm{l}$. The plasma cortisol was $717.6 \mathrm{nmol} / 1$ which is the upper normal limit. The 24 hour urine hydroxy- and ketosteroid outputs were normal and thyroid function tests were normal. Skull and chest radiographs, EEG, and echoencephalogram were normal. No further diagnostic studies were performed. The patient was given acetazolamide, $500 \mathrm{mg}$ per day. Cessation of diplopia and transient obscurations of vision, and marked diminution of headache occurred after the lumbar puncture. Neurological, funduscopic and visual field examinations were normal three and 14 months after discharge (Fig. 2).

\section{CASE 3}

A 28 year old woman developed headache and transient obscuration of vision for three weeks before her admission to the hospital. She had mild bifrontal headache as well. The physical examination was
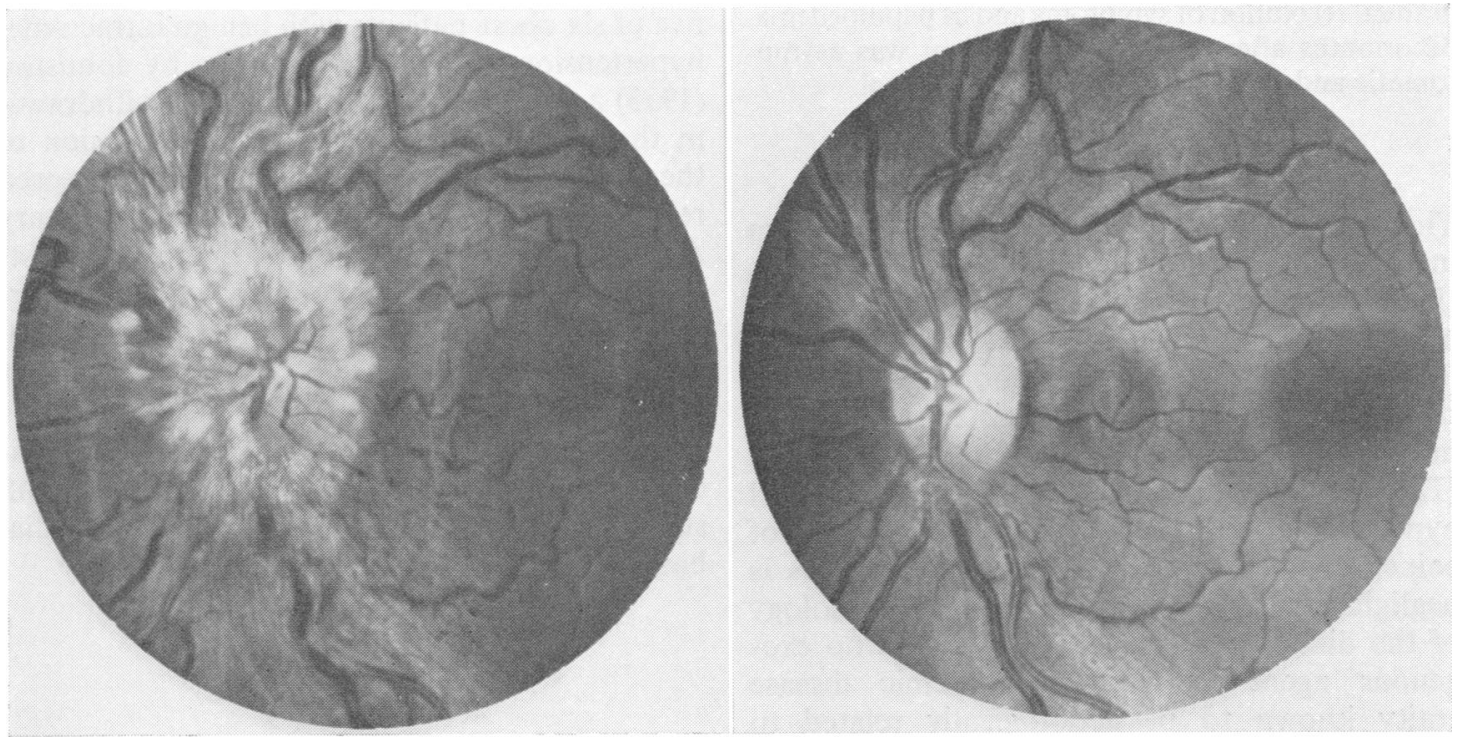

FIG. 1 (left) Case 2. Left fundus during hospitalization showing papilloedema. FIG. 2 (right) Case 2. Normal left fundus 14 months after discharge from hospital. 
TABLE

THREE SISTERS WITH BENIGN INTRACRANIAL HYPERTENSION

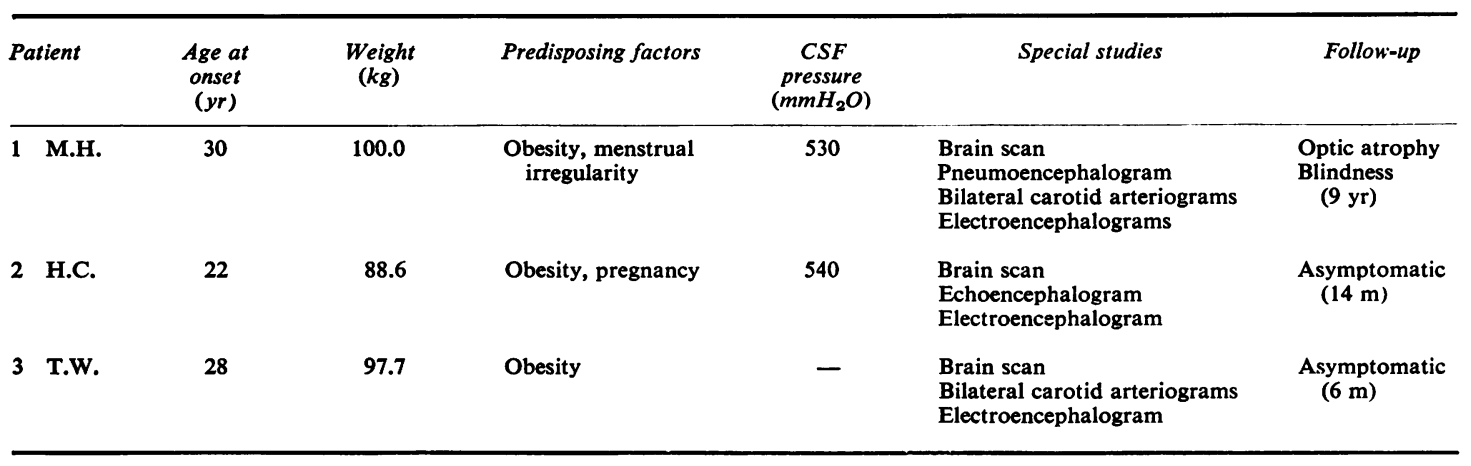

normal except for the weight of $97.7 \mathrm{~kg}$ ( 215 pounds) and the presence of $4+$ papilloedema without haemorrhages bilaterally. The visual acuity and visual fields were normal except for enlarged blind spots. There was no history of any predisposing factor of pseudotumor cerebri. Routine blood studies were normal. Chest and skull radiographs, bilateral carotid arteriograms, and brain scan were normal. The patient was given methylprednisolone, $32 \mathrm{mg}$ per day, for one month followed by tapering dosage to a maintenance of prednisone $5 \mathrm{mg} /$ day. The medication was stopped four months after discharge. Several examinations during this time revealed gradual resolution of symptoms and of papilloedema. Six months after discharge the patient was asymptomatic and the optic discs appeared normal.

\section{DISCUSSION}

Three previous reports have described benign intracranial hypertension in family members (Bucheit et al., 1969; Howe et al., 1973; Rothner and Burst, 1974). Two female siblings were affected in two reports and a mother and son in the third. The present report is the first documentation of this illness in three family members (Table). The prevalence of benign intracranial hypertension is unknown but the probability of coincidental occurrence in these three sisters is negligible. A genetic defect is a likely aetiology of the disorder in these patients, since no exogenous agent or common systemic disease entity known to be aetiologically related to benign intracranial hypertension was present.

Obesity is a common abnormality in the reported patients with familial benign intra- cranial hypertension. It was present in five of the six reported familial patients and is a striking feature in the three sisters reported here. Severe chronic dysfunctional uterine bleeding and pregnancy present in two siblings just describef were not noted in the previous cases. Searches for a definite aetiological link between obesity and benign intracranial hypertension have been unsuccessful. Two separate reports suggest suclb a link but require confirmation. Oldstone (1966) used the metapyrone test to demonstrate deficiency of anterior pituitary ACTH reserve in five of six obese patients with benign intracranial hypertension. More recent studies by Johnston (1973) have shown that acute steroid withdrawal in the rat, producing persistent suppression of the pituitary ACTH reserve, results in increased resistance to CSF outflow. Defective pituitary ACTH reserve with subsequent increased resistance to CSF absorption and intracranial hypertension has been hypothesized as the pathophysiological mechanism in these patients (Johnston, 1973).

Study of future cases of familial benign intracranial hypertension may be particularly fruitful, since a metabolic defect may occur on a familial basis in these patients.

\section{REFERENCES}

Bucheit, W., Burton, C., Haag, B., and Shaw, D. (1969). Papilledema and idiopathic intracranial hypertension: report of a familial occurrence. New England Journal of Medicine, 280, 938-941. 
Greer, M. (1968). Management of benign intracranial hypertension. Clinical Neurosurgery, 13, 161-174.

Howe, J., Saunders, M., and Clarke, P. (1973). Familial benign intracranial hypertension. Acta Neurochirurgica, 29, 173-175.

Johnston, I. (1973). Reduced CSF absorption syndrome. Lancet, 2, 418-420.

Johnston, I., and Paterson, A. (1974). Benign intracranial hypertension. 1. Diagnosis and prognosis. Brain, 97, 289-300.

Oldstone, M. (1966). Disturbance of pituitary adrenal inter-relationships in benign intracranial hypertension. Journal of Clinical Endocrinology, 26, 1366.

Rothner, A., and Burst, J. (1974). Pseudotumor cerebri: report of a familial occurrence. Archives of Neurology (Chic.), 30, 110-111. 